tion of very offensive sputa, rusty-brown in colour. The left side of the chest was dull, but some limited cavernous breathing was heard at parts. The heart beat in its usual position. This man had been long ill, and the case seemed one of cavities in the left lung, containing purulent offensive matter. On Sunday this man was in a state of great collapse and prostration, with copious fotid expectoration. On Monday he was better. On Wednesday he had rigors, clammy sweats, and very feeble pulse. On Thursday he died. The post mortem examination showed the left pleura quite full of stinking purulent matter, the lung being pressed back against the spine. There were some adhesions, and these were so arranged as to fix the pericardium and heart in situ. Had the adhesion been absent, the heart might have been pushed over to the right side and the diagnosis less obscure.

CASE III. - A respectable man engaged in a shop in Regent Street, aged 44, when seen by me at my house on August Ist, 1870, looked very sallow, but in no way emaciated ; indeed, he said that he had been becoming rather corpulent of late. It seemed he had been ill about one month, and he believed he was suffering from stomach and liver derangement. He had a cough, and had been at the sea-side without deriving any benefit. My own faith in the restorative powers of pure seaair in all complaints of mere exhaustion and debility is such that, when a patient returns from a month by the sea no better, or even worse, I suspect some seated disease in the system. The great complaint made by this man about his cough was, that for the whole month past he had, at times, coughed up sputum so offensive as to render the room in which he was quite unbearable. He had shortness of breathing; the pulse was 104; the tongue foul. An examination of the chest disclosed dulness at the right base up to the line of the nipple, and extending downwards a little below the ordinary limit of hepatic dulness. The respiration at the base of the right lung behind was bronchial, with some crepitation. In the left lung there was strong loud breathing. I advised him to inhale the fumes of carbolic acid from a vaporiser, and gave him quinine with dilute hydrochloric acid. A few days later, crepitation was marked at the right base, and a few crepitant rhonchi were heard at the left base also. Beneath the clavicle the respiration was weak. He went daily to his business. On August I2th, he called on me in great alarm on account of free hremoptysis. An examination of the chest showed the breathing harsh and strong at both bases, and much less crepitant rhonchus. I told him to keep quiet at home, gave him opium at night, and creasote with acetic acid during the day. The foetor of the expectoration had almost totally subsided since he had used the inhalation of the vapour of carbolic acid from one of Savory and Moore's carbolic acid vaporisers. On August 22nd he was taking iron and quinine; the pulse was 84. There was less dulness over the right base, but some pain at times on the right side; and he said he did not think I need see him again. A few days later, I left town for three weeks. I heard no more of him till October 1870 , when he called in consequence of a sudden attack of hæmoptysis, after taking a long walk and eating raw apples. His pulse was 88 . There was dulness still at the lower right third of the chest; the breathing was very weak now, where before it was bronchial. At the left base there was strong full respiration; the sputa were not foetid. This was on November I 9 th. I next saw him in bed, in consultation with Dr. Brown, his regular attendant, on Sunday, January 22nd of this year. He said that on the previous Thursday, as he left the omnibus to walk to his house at Camden Town, he felt sudden severe pain in the chest; and when I saw him I found him lying in bed on his back, with no severe dyspnœa, respiration 40 , pulse 132. The right back was perfectly dull; and when I moved him and listened afterwards, a distinct metallic tinkle was heard. I considered that a subpleural abscess must have burst into the pleura, causing a false empyema. The dyspnca being by no means urgent, I prescribed some ordinary remedies, and suggested that it might be well for me to see him again should his difficulty of breathing increase; my intention under these circumstances being to propose paracentesis of the right chest. A week later (Saturday evening), a message was left at my house that the patient was dead. I called on the following afternoon, prepared with instruments for a post mortem examination. Dr. Brown soon came, and we together made the examination. When Dr. Brown cut through the cartilages on the right side of the thorax, at once a puff of very foetid gas escaped; and on opening the chest the right side was full of stinking grumous purulent fluid, which $I$ ladled out to the extent of a chamber-pot quite full. The right lung was then seen as a mere thin skin pressed against the spine, leathery, airless, covered with creamy pus, and on spreading it in a plate we could trace a cavity, or rather sac, in its lower lobe. The left lung was voluminous and congested. Nothing like a tubercle was seen in either lung. The liver was large, but not unhealthy. I was interested in this point, for the very basic character of the disease in the first instance, the fact of the right side being affected, the sallow, but by no means emaeiatcd, look of the patient, made me think more than once of the case of a man admitted to Victoria Park Hospital many years ago with profuse purulent expectoration, where a post mortem examination showed that an hepatic abscess had ruptured through the diaphragm and been discharged by the bronchial tubes. Against such a probability in the present instance I set the rarity of hepatic abscess, the rarity of its opening through the diaphragm, and the fact of the dulness increasing rather upwards towards the axilla than downwards towards the abdomen. With respect to remedial treatment, the inhalation of the carbolic acid vapour I may describe as strikingly beneficial against the fotor, and the power of opium and also of digitalis over the attacks of hæmoptysis was unmistakably marked.

Inquiry into the early history of case III elicited nothing more definite than the statement that he had for a long time had cough and much expectoration every morning. Ulceration of the air-tubes must have taken place, soon after which event probably it was that the sputa became not only fotid, but mixed freely at times with blood. More than once during my attendance I mentioned this sequence of events as my opinion; and, in answer to inquiry, I decidedly negatived the idea of tubercle of the lung. During the last week of the patient's life, as well as for several weeks previously, there had been no return of the fœtor in the sputum, which was tough, and greenish at times. The large amount of fluid found in the right pleura seemed to have increased rapidly during the last week of life, and must have been caused by the lung-mischief extending from within outwards.

The prospects of paracentesis in these forms of pleuritic effusion and false empyema are not promising : the question, however, is one on which more practical experience is wanted. My own opinion would be favourable to the operation, as one that would rid the patient of $a$ dangerous and pernicious matter within the chest, and would thus afford him, at any rate, a chance of recovery which he would hardly have while he was carrying about, pent within his chest, an accumulation of offensive fluid.

In conclusion, I may observe that the events which I mentioned as probable, or rather possible, in Case I-viz., hæmoptysis and pneumothorax, actually did occur in Case III. The prominent symptom of the fotid expectoration is the one to which I would especially draw attention in reference to its relation to these forms of pleuritis.

\section{EXFOLIATION OF THE BLADDER,}

BY T. SPENCER WELLS, F.R.C.S.,

Surgeon to the Queen's Household, and to the Samaritan Hospital.

DR. WARDELL's interesting case reported in the JOURNAL of June Ioth, with his paper and that of Dr. Phillips in succeeding numbers, have induced me to send to the museum of the College of Surgeons two specimens, which I have asked Mr. Flower to place where they may be conveniently inspected by any of the Fellows who may attend the College election next Thursday, and who may be interested in the subject. Another specimen (No. 1993 Pathological Specimen) in the museum referred to by Dr. Wardell, from the bladder of a man, which Mr. Liston opened by incision above the pubes, may be seen at the same time.

In one of my specimens, the uterus and bladder are seen, as well as the detached cast of the bladder, covered with a gritty deposit of urates and phosphates. The walls of the bladder are thick and contracted, the muscular fibres being distinctly visible. The detached mass which was lying loose in the bladder I described at the time as "degenerate epithelium holding together saline deposit. On boiling a piece of it in twenty parts of water to one part of acetic acid, much of the saline matter is dissolved, and some of the tissue becomes clear, looking like smooth muscular tissue which has begun to degenerate by the deposit of fatty or albuminous particles in its substance." (Obstetrical Transactions, vol. iii, p. 354).

The patient was twenty-two years of age. After a natural labour with her first child, the bladder was not emptied for sixty-two hours. Five pints of turbid bloody urine were then drawn off. Cystitis followed, incontinence of urine, and a train of distressing cerebral symptoms, ending in death two months after delivery.

The second specimen I exhibited at the Obstetrical Society on the evening of the day when it was voided by the patient, six weeks after a severe instrumental labour. The report may be seen in the third volume of the Obstetrical Transactions; and in the fourth volume there is an elaborate report on the specimen by Dr. Harley.

From the time of her labour the patient suffered from severe cystitis with nephritis. Three weeks after labour, the urine contained albumen, blood-corpuscles, pus-cells, chylous matter, and renal tube-casts. 
The urine, when quite fresh, was loaded with carbonate of ammonia. A hard swelling had been felt through the anterior wall of the vagina; and on the day before the specimen was expelled through the urethra, Mr. Marshall, the surgeon in attendance, had observed shreds of sloughy membrane protruding through the urethra. After it came away, the health of the patient rapidly improved. I have lost sight of her; but Dr. Harley saw her in good health between two and three years after the illness.

My second specimen differs from the first in being a more complete exfoliation of the bladder. It is a bag of animal membrane-involuntary muscular fibres interlacing over its outer surface-the interior being a smooth mucous surface, covered with crystalline phosphates and urates.

The case referred to by Mr. T. Smith in the thirteenth volume of the Pathological Transactions, page 150, was, as I believe and said at the time, a similar case to these ; but two very competent observers reported that they had "no doubt the membrane in question is the bladder of some animal, most probably that of the bullock; and that it has not been passed in the manner which the patient represented."

It is evidently of great importance that the true nature of these cases should be recognised; for the recovery of my second patient would encourage us in a male patient to follow the example set by Mr. Liston, and remove the foreign body. In a female this might probably be done by forceps alone, and certainly if the urethra were previously dilated.

\section{CLINICAL MEMORANDA.}

\section{CAN MERCURIAL TREMORS COEXIST WITH CHRONIC LEAD-POISONING ?}

THE two following cases may be interesting to the readers of the JouRNAL in regard to the above query.

George B., aged 26, a looking-glass silverer, came under my treatment in February last. $\mathrm{He}$ was a poorly nourished man, with a fair complexion, and was suffering at the time from severe muscular tremors. The muscles chiefly affected were those of the upper extremities; and in conjunction with the tremors there was great weakness of the muscles of the hands (especially of the extensors), so that he was totally unable to feed himself and perform various minor offices without assistance. With these symptoms pointing to the muscular system, he also had slight ptyalism, sponginess of the gums, and great foetor of the breath. The anomalous part of this case, however, remains to be described. Along the edge of the gums surrounding the incisors of both jaws was a very distinct blue line; and in association with this phenomenon I may mention that he had griping pains in the abdomen, although the bowels were not greatly confined. $\mathrm{He}$ was treated with three-grain doses of the iodide of potassium three times daily, and was told to abstain from following his employment. I saw him afterwards at intervals of a week or ten days until May last. The muscular tremors, the foetor of the breath, and the sponginess of the gums, rapidly disappeared-not so, however, the blue line surrounding the incisors, and the partial paralysis of the extensors of the fore-arms : these symptoms still persisted, although in a modified degree, even at his last visit. In my inquirie concerning the nature of his employment, I elicited that the tin-foil used in silvering contained a considerable percentage of lead in its composition.

In May last, John C. came under my treatment suffering from colicky pains in the abdomen and constipated bowels. He had been employed for the last five years at tin-foil works. Upon examining his gums, I found a slight blue line beneath the lower incisors. There was no paralysis in this case. This patient also confirmed the statement of George B. as to the employment of lead in the manufacture of tin-foil. Cessation from work and small doses of Epsom salts, combined with diluted sulphuric acid, two or three times daily, rapidly relieved him.

From the symptoms present in the first case and their subsequen mode of retrogression, we must conclude, I think, that two poisons were simultaneously affecting the system ; and, consequently, we must rather ascribe the blue gum line to the lead than to the mercury, although the black sulphide of the latter metal might, theoretically, be supposed to give rise to such a phenomenon.

53, Harley Street, W., June 19.

W. Ainslie Hollis, M.D.

THE fatal cases of small-pox in London, which in the three previous weeks had been 257,229 , and 245 , were 240 last week. The fatal cases showed an increase in the East of London, a decline in the West and South, and but slight variation in the North and Central Districts.

\section{REPORTS \\ OF}

MEDICAL AND SURGICAL PRACTICE IN THE HOSPITALS OF GREAT BRITAIN.

\section{NOTES ON THE TREATMENT OF GANGLION IN THE LONDON HOSPITALS.}

THE treatment of the common affection called ganglion, simple as it may appear and is generally supposed to be, is still a subject on which a very considerable difference of opinion exists amongst surgeons, as may be seen by a perusal of the following notes. It was with the view of gathering the opinions of hospital surgeons on the various methods of treating this affection, that we thought of collecting a few notes on the subject. We have been by their kindness enabled to obtain a mass of valuable information, containing the experience of most of the London hospital surgeons; and shall endeavour to procure similar notes from provincial hospitals and from Scotland and Ireland. We shall be glad to receive at the same time short notes of interesting cases of ganglion, for publication, in connexion with our report on the general treatment of the affection.

KING'S COLLEGE H OSPITAL.

Mr. JоHN WoOD treats ganglion by the following plan. A spearpointed needle, cutting on both edges, and mounted on a handle, is passed into the cyst, and made to transfix it again and again, so as to let out the synovial contents into the areolar tissue of the surrounding fascia. The needle is then made to scarify briskly the interior of the cyst, and is used pretty freely in dividing the cyst-wall at its opening of communication with the sheath of the tendon. Pressure is then made with both thumbs upon the tumour, so as to squeeze out completely its contents, partly into the subcutaneous areolar tissue, and partly out through the opening in the skin by which the needle entered. Iodine paint is then applied thickly over the surface, and upon it a thick pad of lint, over which firm pressure is made by a bandage. This is kept on for several days, after which the iodine paint is again applied, and the pressure readjusted. After a few applications in this way, the tumour seldom reappears; and, if it do so, a repetition of the process rarely fails to succeed. No case has been met with, out of many hundreds treated, in which suppuration or any bad results have followed this plan; but several cases in which a seton had been employed have given rise to much trouble and danger from erysipelatous inflammation and abscesses, followed by stiffening, and in some cases permanent impairment of the use of the limb.

Mr. HenRy Smith meets with a large number of cases of ganglion in the out-patient department of the hospital. After having tried various means of cure, he has come to the conclusion that the most effectual is that of operation by the seton. He passes a single ligaturethread through the cyst, and allows it to remain according to circumstances. In some instances, severe inflammation and even suppuration will be produced in forty-eight hours, and then the thread is to be withdrawn. In the majority of instances, however, especially when patients are careful not to use their hand, the seton may be retained for a period varying from three days to a week or more, without producing any inconvenient symptoms; but, so soon as suppuration takes place, Mr. Smith withdraws the thread, and the cure is almost invariable. It is necessary to bear in mind in this treatment, that, in some constitutions and under certain conditions, the presence of the seton may produce very severe consequences ; in fact, this is the only objection to the treatment. With care, this rarely occurs; and there has only been one instance amongst Mr. Smith's patients at the hospital where bad results did happen. This was in the case of an unhealthy man who applied with a ganglion as large as a crown-piece on the back of the wrist. Mr. Smith passed a seton. The patient did not apply until after four days, and in the meantime most violent inflammation and suppuration occurred. Free incisions were necessary, and the wrist-joint itself was threatened for a time; but the use of a splint and careful treatment prevented any mischief. The patient, however, was compelled to remain under treatment for several weeks.

Mr. Royes BeLL often finds that a ganglion is too tough to be burst by any reasonable amount of external pressure, or is so situated that this form of treatment is not applicable; and that it may be radically cured by a puncture with a grooved needle, squeezing out the contents as perfectly as possible, and rubbing the sides of the cyst together. Firm pressure must be applied by means of a pad formed of lead, gutta 